\title{
Healthcare supply chain for China's Belt and Road Initiative during COVID-19
}

\author{
Ruili Yao ${ }^{1, \mathrm{a}}$, Fangyu $\mathrm{Mei}^{2, \mathrm{~b}}$, Xue Wei ${ }^{3, \mathrm{c}}$ \\ ${ }^{1}$ University of Illinois at Urbana-Champaign \\ ${ }^{2}$ Oregon Episcopal School \\ ${ }^{3}$ University of Sydney
}

\begin{abstract}
COVID-19 paused people lives and recombine various industry operation system. The China's Belt and Road Initiative have been intensively studied for their role in healthcare industry, the nations among them came together to defeat COVID-19 by building new healthcare system for protect public health condition. Pandemic periods inspect the previous healthcare supply chain system inefficiency in the operation situation matches with the current social development. This article compares the traditional healthcare supply chain management and novel one developing with the medical pandemic. Simultaneously, the new supply chain process illustrates the new pattern healthcare supply chain under COVID-19 in China's Belt and Road Initiative countries. Taken together, the results of this article, potentially representing a novel healthcare supply chain developing process during pandemic in China's Belt and Road Initiative.
\end{abstract}

\section{Introduction}

The China's Belt and Road Initiative is the silk road economic belt in 21 century maritime silk road, which a project between countries built during October 2013. It is a cooperation platform relying on the existing bilateral and multi- lateral mechanisms between China and relevant countries. After the opening of the Belt and Road initiative economic zone, the number of contracted projects exceeded 3,000 cases. Chinese government undertook 17.83 billion us dollar in service outsourcing contracts from countries related to the Belt and Road initiative. The executed value exceeds US 12.15 billion dollars, an increase of 42.6 percent and 23.45 percent annual respectively. At the end of June 2016, a total of 1,881 trains were opened for China-Europe freight trains, including 502 re- turn trips, and achieving a total import and export trade volume of US 17 billion dollar. China's Belt and Road Initiative and China economic strategy are also related to global governance. Aspect of the China's Belt and Road Initiative related to global governance is its fostering of collaboration with the international institutions. The vague definition of China's belt and road Initiative also enables the Chinese government to make necessary adjustments and adjust its work priorities. As early as 2015, Chinese health authorities put forward policies and proposals to strengthen international health cooperation in the field of the China's belt and road initiative on people-to-people exchanges. Increasing health infrastructure ensures society economic development. At same time, in recent years, there is a significant increase foreign investment in Chinese enterprises healthcare and pharmaceutical industries, which is regarded as the basis of cooperation between China's belt and road initiative in healthcare industry. The industry reached 4.2 billion US dollars in 2017, that compares with 130 million dollars in 2014 (xing, 2017). Many of these investments are strategic acquisitions by foreign pharmaceutical companies, medical device manufacturers and private medical service companies. China also welcomes foreign investment Chinese health authorities. According to the report Deloitte China (2017) 2012- 2016 China received 12.35-billion-dollar foreign investment in China's medical in- destroying pharmaceuticals, biotechnology, medical equipment manufacturing and healthcare Service industry. These investments are momentous strengthening capacity building in high-tech medical equipment manufacturing and drug pro- duction.

After China's Belt and Road Initiative was put forward into healthcare industry, Chinese government established the Silk Road Economic Belt Medical Service Center in Xinjiang. Relying on Xinjiang's geographic advantages in bordering 8 countries and leading medical standards in the surrounding countries, China strives to build an international medical center for neighboring countries and strengthen foreign exchanges and cooperation in the field of medical services. From the establishment of international medical service department, people who in relevant languages joint the opening" green channels" with the good technology, low fees, and cultural. The geographic advantages of Chinese hospitals have attracted many patients from neighboring countries to come for treatment. With the establishment of the service center, there are more and more exchanges and visitors in the medical field.

ayuhangm2@illinois.edu, ${ }^{b}$ meif@go.oes.edu, ${ }^{c}$ xwei5275@uni.sydney.edu.au 
Under the COVID-19, economic and trade cooperation along the China's Belt and Road Initiative has been impacted, the impact is relatively humongous, and the COVID-19 has spread all over the world and cause insurmountable effect. Lots of countries are facing economics recession and healthcare industry collapse and must close up to protect citizens. From the report of the World Health Report, until October 18Th,2020, there has been more than 40 million people confirmed infected for COVID-19 and more than 1.1 million people died because of this pandemic. The increasing trend of COVID-19 did not show any decrease. In the past week, there are more than 2.4 million new cases and cause 36000 more deaths. In the past few months, even though there has shown a trending of decrease, the number is still high, and the protection still has to be made in the majority of the world. The COVID-19 has had an enormous effect on every industries in the world, especially the healthcare industry be- cause they are the ones that have to stay in the front line and save millions lives people.COVID-19 has led to overworked doctors, a sharp shortage of PPE and medical equipment, drug shortage and disrupted transportation of supporting medical supplies which influence seriousness COVID-19 curative ratio. The pandemic is a serious blow to the traditional supply chain system.

\section{Healthcare Supply Chains}

In the traditional healthcare supply chain system, the full version of information between suppliers, manufacturers, distributors, and customers. Shah(2004) pro- vides detailed descriptions of the characteristics of these supply chains Information about typical performance levels. There is a long lead time. It takes 1,000 to 8,000 hours for the product to travel through the entire supply chain. At the same time, inventory levels appear to be quite high, with inventory turnover be- tween one and eight weeks. This is consistent with the findings of Haavik (2000), who reported in 1994 that. In the healthcare industry, the supply chain associated with drugs is medicines Pharmacy medicine. In terms of cost, it is estimated that supply will account for 25-30 percentage, It is essential to ensure a high standard of care and an adequate supply As a percentage of hospital operating costs (Roark 2005). The product flow in the healthcare sector (Figure2) starts with the manufacturer and ends with the healthcare provider's end customer. Depending on the type of product, the product can be delivered directly by the manufacturer to the healthcare provider or delivered through the distributor before reaching the healthcare provider. Healthcare supply chains are often described as highly decentralized and relatively inefficient (Schneller and Smeltzer, 2006). A major problem with traditional healthcare supply chains is that each stage of the supply chain operates independently, resulting in in- consistent incentives and conflicting goals that prevent the supply chain from operating as a system. These conflicting goals, along with other obstacles, have hindered the adoption and implementation of supply chain management practices.
(Joseph Mathew, Joshin John and Dr. Sushil Kumar) The turnover of the hospital stock lasted four to five weeks. The system is so weak under the context of a global health emergency, it is extremely vulnerable. A common problem is when emergency orders and wholesalers are out of stock. If the product reaches critical inventory levels, an emergency order can be placed. It happened as a real case during COVID-19 outbreak in 2020.

According to the charterer of COVID-19 and technological innovation, social distance and remote working lifestyle gradually influence social behaviors all around the world. Healthcare industry is the most related filed. The physical hospitals are overload operation and high risky COVID-19 inflection during the pandemic, it brings the internet diagnostics as more effective and reduce infection rate. Thus, the healthcare provider convent patient's demand to distributor or producer directly, which shorter the supply chain process. Meanwhile, it can promote virtual centralization of the supply chain (Schneller, S. Eugene S., Larry R. Smeltzer. 2006), collaboration using virtual centralized supply chain management lead hospitals on the path of cost control and service improvement. Virtual centralization integrates operations from a market perspective rather than from a health system perspective. Online Hospital or clinics estimated the number of patients in advance, the drugs needed, and summarized patient data. Meanwhile, all those patient's data had been recorded by location, age, gender, pharmaceuticals use, medical devices history, and all other data. And because we have all this useful data information to lay the groundwork, Under Vendor Managed Inventory (VMI), the supplier assumes responsibility for the management of inventory at the customer and takes decisions regarding replenishment (Waller etal. 1999). The main difference is that the responsibility for inventory control is transferred to the supplier because the ordering process is still automated by the patient's database.

\section{Prospective healthcare supply chain process}

It is great opportunity to rarely and patients' relatively concentrated surroundings, to achieving virtual centralization supply chain in healthcare industry. Before the COVID-19, each hospital clinic is responsible for scheduling daily patients' reception by queuing situation or long-term waiting lists appointment, ordering the pharmaceuticals by each locations inventory. Thus, each individual healthcare is monitoring and managing their own inventory and they place an order to the wholesaler when required. The decision on which products to order at each period and the quantity required relies upon the experience and skill of staff at the clinics. There are two new models of change in the healthcare supply chain industry. One of the prospective internet healthcare provider processes as follow. Patients fulfill the appointment request at any location by cell phone application by booking online registration. Checking in mobile terminal achieve no contact register at central front desk. Through the hospital navigation system, the 
doctor goes over patient's health history and checklists, triage system order, and push patient's lab examination order to labs system. After the test specimens transport to the laboratory by automatic logistics system, the test results came out. Patients print report through selfservice terminals after all reports which are generated by mobile terminals. After the doctor reads the report, he/she prescribe the medicine to the patients' Picture Archiving and Communication Systems. The patient make payment through application or self-service terminal and then generate the drug collection number. At this time, the smart pharmacy has automatically issued the medicine according to the drug application submitted by the system. The patient collects the medicine from the pharmacy with the drug collection number. After leaving the hospital, patient updates medical condition at any time through the follow-up system on the application. Doctors review the patient's condition through the application at any time. The dean of hospital understands the operation dynamics of the hospital in real time through the hospital intelligent decision-making system and see relevant data. Medical students use cloud computing platform to extract massive stored clinical data for clinical research. Logistics managers monitor the status and inventory of medical equipment in real time through the whole life cycle of equipment management system, that is realize the fine management of hospital equipment.

During COVID-19, the following increasingly optimized procedures accelerate new forms of healthcare supply chain process. Ping An Healthcare and Technology had the process referred to below details healthcare supply chain management practices during COVID-19 in China. It is not only process virtual centralization supply chain, but also initiate during the diagnosis stage. Ping An Healthcare and Technology launched the online clinic since 2015, design and accomplish 724 Hours online medical consultation, electronic prescription, one hour pharmaceutical drug delivery in city area and same day pharmaceutical drug delivery in suburban area specialized central system, dominant supply chain system based on the central system analysis and pharmacy partners rely on the central warehouse to achieve lightning delivery. First, doctors associate with solve the problem of difficult access to medical services in remote areas on internet clinic and improve the efficiency of medical treatment. Second, pharmacy sharing pharmacies to solve the problem of drug inconsistency within the medical community, which evaluate the performances of prescription automatic screening system (PASS)The third is $5 \mathrm{G}$ remote ultrasound, real-time diagnosis, the people in the small hospital or at home can get the third grade hospital ultrasound diagnosis. An ultrasound specialist contemporary works with a local doctor to diagnose the patient. Fourth, the independent microclinic is convenient for people to make prescriptions. Patients with chronic diseases can go to the cloud clinic to order medicines, and then ask doctors to make prescriptions online, and then use the distribution system to send medicines home. Below shows the data difference between normal national medical intuitions in China and Ping An Health and Technology by the patients diagnostic, duration and cost with RMB.

Table1: difference between normal national medical intuitions

\begin{tabular}{|c|c|c|c|}
\hline Compare item & Patients diagnostic & Duration & Cost/RMB \\
\hline Nation Medical Center & 24 million & $120 \mathrm{~min}$ & 290.80 \\
\hline Ping An Health Tech & 0.73 million & $20-35 \mathrm{~min}$ & 83.16 or less \\
\hline
\end{tabular}

From the most recent data compare, the capacity of patients diagnostic is still have capacity to improvement of Ping An Health and Technology, but the duration period of Ping An Health and Technology is much supersonic than normal medical center by distinguished technology and system applications. Meanwhile, the cost during the diagnostics period, it had been reduced at lease

3.5 times, it isathe huge reduce for small symptoms disease or physical concern. It is obvious that the new healthcare diagnostic system has a positive correlation between the efficiency of the overall visit process and future growth. It is so essential process enhancement during pandemic in healthcare industry.

Throughout the pandemic time, Ping An Healthcare and Technology cooper- ate with couple China's belt and road Initiative countries in healthcare supply chain practice and sustenance. Indonesia is one of the important countries in China's Belt and Road maritime transit cooperation country. Over the past five years, the two sides have actively reinforce their development strategies and comprehensively deepened cooperation, and yielding fruitful results. Pending the COVID-19 healthcare outbreak, Ping An Healthcare and Technology is highly recognized by Indonesia government, and the Indonesian Ministry of Health and the Association of Doctors signed a cooperation agreement of new healthcare supply chain system for improving the patient reception ability. Bring Ping An Good doctor online clinic platform in Indonesia market, which are connect to local hospitals, doctors, medicines stores, logistics distribution and other strategic partners for users providing one-stop online medical and health services; it had given consultations reached average 4000 people per day at the first month. Ping An Healthcare and Technology launched medical ecological layout in the Middle East -in collaboration with the Saudi government has designated company Lean, customized design online health services in" AI + Internet medical" layout. At the same time, it carried out the innovative business model, adopts the new technology licensing model, based on own AI technology to exploit the licensed mode technology oversea, which depth effect to Saudi medical system and to prepare the new model healthcare supply chain. 


\section{Challenges and Opportunities}

The global economy is expected contract by 3 per cent this year and cumulative GDP losses over the next two years could exceed 9tn dollar.COVID-19 has severely affected the global economy, affecting manufacturing, supply chains and the movement of people and goods. Most advanced economies countries are expected to contract by about 6 percent. At same time, China's GDP fell 6.8 percent at the first epicenter of the COVID-19 outbreak a year earlier, which its first economic contraction in decades. Some Belt and Road Initiative countries have closed factories, turning manufacturing capacity into medical production, and disrupting vital supply chains, including China those supplying with construction machinery and materials. Meanwhile, due to the pandemic, most countries perform travel ban policy, it slows it down global supply chain disruptions, blockades and trading restrictions on trading, causing daily life products and commercial shortage, even the healthcare personal protective equipment and pharmaceuticals or raw materials for pharmaceuticals deficits. Traditional healthcare supply chain system was on the verge of collapse and is exhibiting intonation regional faults. Due to Chinese world factories in all the business industries, the scores factories and logistics interruption cause temporary sup- ply chain disruption. The healthcare industries appear medical devices shows catastrophic shortage.

There are many challenges that the new healthcare supply chain system might not apply to all hospitals or market. First of all, the economic in underdevelopment regional of the new healthcare supply chain system is limited. It would be impossible for all underdevelopment countries hospitals ensure the internet system operation since some hospitals even not have the internet re-source. The whole system need huge amount of money as the economic support that hospitals adjust traditional supply chain system. Secondly, using the new healthcare supply chain system required professional technology skills, it officially desire lots of technical employee to ensure the technology system and equipment install correctly and training healthcare staffs understood. Furthermore, the corollary equipment and money are the most defining factor of the internet health care supply chain. Without the enough amount of capital preparation, the hospital is not maintaining this supply chain for a long period of time. At that moment, the hospital faces an awkward situation and serious problems since both the new health care system and the traditional one are not fully developed. To develop the new form of health care supply chain, these three factors could all become the difficulties to realize the supply chain in all hospitals.

Many of China's belt and road initiative's projects are in developing countries, where containing the epidemic and promoting recovery may be more difficult than in developed countries. The pandemic also exposed the response capacity of public health in the most China's Belt And Road Initiative countries, according to the World Development Indicators, which their poor performance in the most basic health indicators. This means that in the coming years, China's Belt and Road
Initiative countries will invest heavily in hospitals and laboratories to make up for major gaps in their health systems. So after the outbreak, the health silk road will become an important part of the China's Belt And Road Initiative countries. The success of China's silk Road for Health depends on its rapid expansion in China's Belt and Road Initiative countries to cope with China's growing assertiveness. The Belt and Road healthcare project will increasingly focus on lucrative supply chain opportunities between China's Belt and Road Initiative countries, where the private sector and private capital will play a greater role.

\section{Outlook}

New technology improves efficiency, optimizes quality, and facilitates accessibility by changing production methods and revolutionize healthcare supply chain. The change of underlying technology not only brings internal hospital productivity leap, but also leads diversify the whole healthcare process. The bottom-up reform of the healthcare supply chain system converts technological development swept across the world. Intelligent hospital construction based on artificial intelligence, information technology, Internet data, Internet supply chain and other new technologies has become the only way for future healthcare industry development. It is a catastrophic moment for all the countries in the world. The people we lost, the economic infected, and the horrible period we suffered are worth to been remembered. During this pandemic, the old healthcare supply chain system has accelerated the development of medical supply chain towards visualization, data and prediction, providing a practical platform for the new medical supply chain in China's Belt And Road Initiative countries. The collaboration among China's belt and road initiative countries sharing healthcare experimental data and longterm research and observations on COVID-19, that is thoroughgoing domination contribute to the development of new medical supply chains.

\section{Reference}

1. Alfred WuKevin HongKatie ChungJune 2020), The impact of COVID-19 on Belt and Road Initiative infrastructure and construction projectsInternational arbitration report,Issue 14

2. Bartik, Alexander W., etal (2020) The impact of COVID-19 on small busi- ness outcomes and expectations. Proceedings of the National Academy of Sci- ences 117.30 : 17656-17666.

3. David Ramirez, Independent Consultant, COVID-19: Global trade and sup- ply chains after the pandemic

4. Deep PalRahul BhatiaSuchet Vir Singh, Health Silk Road 11 June, 2020 1:29 pm IST - How China plans to make BRI essential in Covid-hit South Asia

5. Haavik, S. 2000. Building a demand-driven, vendormanaged supply chain.Healthcare Financial Management. 56-61 
6. Ngeow Chow-Bing, October 2020COVID-19, Belt and Road Initiative and the Health Silk Road:Implications for Southeast Asia Roark, D.C. 2005. Managing the healthcare supply chain. Nursing Manage- ment. 36-40

7. Schneller, S. Eugene S., Larry R. Smeltzer. 2006. Strategic Management of the Healthcare Supply Chain. Jossey-Bass.

8. Shah, N. 2004. Pharmaceutical supply chains: key issues and strategies for optimisation. Computers and Chemical Engineering.28:929-41.

9. Talha Burki, 30 Jun 2020, 2020 Global shortage of personal protective equipment, The Lancet. Infectious Diseases, (7):785-786 DOI 10.1016/s1473- 3099(20)30501-6 PMID: 32592673 PMCID: PMC7314445

10. Waller, M., M.E. Johnson, T. Davis. 1999. Vendormanaged inventory in the retail supply chain. Journal of Business Logistics.20(1):183-203. 